\title{
Oyacılık Sanatı ve Sivas İli Divriği İlçesi Kemenkeş Köyüne Ait Bir Grup Oyanın İncelenmesi
}

\begin{tabular}{|c|c|}
\hline & Ezgi KOÇ* $^{*} \quad$ Mine CAN ${ }^{* *}$ \\
\hline Makale Bilgisi & ÖZET \\
\hline $\begin{array}{l}\text { Makalenin Türü: Araştırma makalesi } \\
\text { Makalenin Geliş Tarihi: 07.6.2021 } \\
\text { Makalenin Kabul Tarihi: } 17.11 .2021 \\
\text { DOI: } \underline{10.54970 / \text { turkuaz. } 949313}\end{array}$ & $\begin{array}{l}\text { Oyalar, yüzyıllardır süregelen tekniklerle ve özellikle kadınlar } \\
\text { tarafından üretilen bir el sanatıdır. Anadolu'da icra edilen } \\
\text { oyalarda kadınların duygu ve düşüncelerini anlam yüklü doğadan } \\
\text { motiflerle ya da başka şekillerde izlemek mümkündür. Giyim- } \\
\text { kuşam ve baş bağlama geleneğinin en önemli aksesuarları } \\
\text { arasında olan oyalar, günlük yaşamda el emeği bir uğraş olarak da } \\
\text { karşımıza çıkmaktadır. Oyalar çeyiz kültürünün en önemli } \\
\text { parçaları arasından olup, bu gelenek içerisinde hediye verilmenin } \\
\text { yanı sıra ekonomik amaçlı olarak da kadınlara gelir sağlamaktadır. } \\
\text { Gelenekler içerisinde Sivas ili Divriği ilçesi Kemenkeş köyünde } \\
\text { bulunan oyaların teknik ve estetik özelliklerini belirlemek amaçlı } \\
\text { yapılan bu çalışma, literatür ve alan araştırmasına dayalı betimsel } \\
\text { bir araştırmadır. Çalışmada veri toplama aracı olarak bilgi formu } \\
\text { kullanılmıştır. Araştırma kapsamında yöre halkından olan kaynak } \\
\text { kişilerle görüşmeler yapılmış ve ürünlerin fotoğrafları çekilmiştir. } \\
\text { Elde edilen bilgiler uygun görülen konu başlıkları altında tablo } \\
\text { haline getirilerek sıklık dağllımları ve yüzdelik gibi istatistiksel } \\
\text { yöntemler içerisinde göreli frekans (sıklık yüzdesi) formülü ile } \\
\text { değerlendirilmiștir. }\end{array}$ \\
\hline
\end{tabular}

Anahtar Kelimeler: Oya, gelenek, el sanatları.

\section{The Art of Needlework and a Review of a Set of Needlework Belonging to the Village of Kemenkeş, Divriği District, Sivas City}

\begin{abstract}
Needlework is a handcraft which has been produced with continuous techniques for centuries, especially by women. It is possible to observe the emotions and thoughts of the women in the needlework made in Anatolian through meaningful patterns coming from the natüre and other shapes. Needlework, which is among the most important accessories for clothes and finery and the tradition of covering the head with scarf, can be found as an handwork interest in daily life. As well as being one of the most important pieces for he dowry culture, it is both a channel of income for women and gift which can be exchanged in this culture. This study, which aims to determine the technical and aesthetic techniques of needlework found within the traditions in the village of Kemenkeş, Divriği District, Sivas City, is a descriptive study based on literature and field research. In the study, information form is used as the data collection tool. Within the

\footnotetext{
* Kocaeli Üniversitesi Sosyal Bilimler Enstitüsü Halkbilimi Anabilim Dalı Yüksek Lisans Öğrencisi, Kocaeli/Türkiye, ezokoc140@gmail.com, ORCID ID: 0000-0003-4807-4351

** Doç. Dr. Kocaeli Üniversitesi Değirmendere Ali Özbay Meslek Yüksek Okulu, Kocaeli/Türkiye, mine can82@hotmail.com, ORCID ID: 0000-0001-6563-7174
} 
research, people from local region have been interviewed and photograps of the products have been taken. The obtained information was tabulated under the appropriate topics and evaluated with the relative frequency (frequency percentage) formula among statistical methods such as frequency distributions and percentages.

Keywords: Needlework, tradition, handworks

\section{GíRiş}

İnsanların var olmasıyla birlikte el sanatları da tabiat koşullarına bağlı olarak oluşmuş ve devamında ilk örneklerini insanların örtünme, süslenme, korunma gibi çeşitli ihtiyaçlarını karşılama doğrultusunda gelişerek çeşitlenmiştir. El sanatlarının en ince ve en zarif örneklerinden birisi olan oyalar, yüzyıllardır süslenme geleneği içerisinde zengin çeşitlilikteki motif ve renklerle kadınlar tarafından değişik tekniklerle meydana getirilmektedir (Aydın, 2015: 768).

Örücülük sanatının başlangıcı kesin olarak bilinmemekle birlikte, ilk insanlardan bu yana var olan ve örtünme ihtiyacı karşılanırken zamanla estetik kaygılardan da yola çıkılarak yaratıcılık dâhilinde gelişen bir sanat olduğu düşünülmektedir (Gümüş ve Uray, 2018: 356). Jackson'ın 1900 yılında yayınladığı "A History of Hand-made Lace" adlı eserinde Antik Mısır buluntuları ile dantelin örme sanatından doğup gelişmiş olabileceği ileri sürülmüștür. Panopolis, Ahmen ve Yukarı Mısır'da bir mezarda bulunan döndürme ve örme teknikleriyle yapılan örneklerle bu iddiasını desteklemiştir. Beebe tarafından 1880 yılında yayınlanan "Lace Ancient \& Modern" adlı eserinde ise Antik Mısırlılar dönemine ait festival veya resmi giysilerde mumyaların üzerinde mavi boncuklu ağ işi süslemeler olduğu belirtilmektedir (Yıldız ve Öğüt, 2020: 127).

İtalyanlar iğne ile üretilen dantellerin mucidi oldukları konusunda iddialı tutum sergilemiş ancak bu iddia Palliser'in (Palliser, 1875) çalışmasıyla birlikte çürütülmüştür. İtalya'dan göç eden Yunanlıların ince ağ işi çalışmalarını İtalyanların geliştirdiği ortaya çıkmıştır. Avrupa'ya ait örgü isimlerinin bazılarının Ege masallarında geçtiği ve bu döneme ait örgü örneklerinin ise balık ağları olduğu belirtilmiştir (Özbel, 1951; Akt. Balkanal, 2014: 46; Yıldız ve Öğüt, 2020: 128). Örme sanatın M.Ö. 2000 yıllarının öncesine kadar gittiği 1905 Menfiz kıyllarında bulunan örneklerden anlaşılmaktadır (Onuk, 1981; Akt. Gümüş ve Uray, 2018: 356). Farklı kaynaklarda ise iğne ile oluşturulan örgülerin 12. Yüzyılda Anadolu'dan Yunanistan'a, oradan da İtalya ile Avrupa'ya geçtiği öne sürülmektedir (Özbel, 1951; Akt. Balkanal, 2014: 46; Yıldız ve Ögüt, 2020: 128). Sicilya'da yaşayan Suriye Arabistan kabilelerinden nakış sanatını öğrenen İtalyanların dilinde to embroider (nakış işlemek) kelimesi Arapçadan türemiş ve Avrupa dillerinde embroidery olarak karşılığı bulmuştur. Bu durumun nedeni daha çok doğuda Türk işi oyah'ların (oya) Fas ve Çin'de ise nakışlanarak ve iplik çekilerek yapılan ürünlerin çalışılması olarak gösterilmektedir (Palliser, 1875; Akt. Yıldız ve Ögüt, 2020: 128).

Özellikle iğne oyasının ortaya çıkıp gelişmesinde en büyük etken İpek Yolu'nun Anadolu ile bağlantısının olmasıdır. Oya kelimesinin başka dillerde karşılığının olmaması, oyanın Anadolu kadınlarına ait bir el sanatı olduğunu göstermekte ve bu sanatın daha çok Türk kültürü içinde değerlendirilmesini sağlamaktadır (Gümüş ve Uray, 2018: 356-357). Anadolu'nun her bölgesinde rastlanan oyalar, çeşitli örnekleri ile görülmekte; yemeni, çember, yazma ve dikdörtgen şeklindeki başörtülerinin çevresini süslemektedir (Sönmez, 2019: 107). Ülkemizde ise danteller kenar danteli niteliğinde süs olarak kullanılmakta, başörtüsü kenarlarına yapılan ince danteller ise bazen oya olarak isimlendirilmektedir. 


\section{OYALARIN TÜRLERİ VE GENEL ÖZELLİKLERİ}

Türk kültürüne özgü ince bir tür dantel olarak nitelendirebileceğimiz oya, süslenme ve süsleme ihtiyacı ile ortaya çıkmış çeşitli örme teknikleriyle iğne, tığ, firkete, mekik gibi araçlar kullanılarak yapılan, dantelden farklı olarak üç boyutlu şekilde de örülebilen, ipek pamuk gibi iplikler ile bazen pul, boncuk vb. yardımcı malzemeler eklenebilen bir el sanatıdır (Kahveci ve Bahşioğlu, 2001; Akt. Yıldız ve Öğüt, 2020: 130).

Türkler, çok köklü bir geçmişe ve zengin bir kültüre sahiptir. Yaşadıkları coğrafya ne olursa olsun içinde bulundukları ve sahip oldukları kültür getirilerinden yola çıkarak el sanatları alanında zengin örnekler vermiştir. Bu örneklerden birisi de oyalardır. El sanatlarının en ince türlerinden biri olan oyalar yüzyıllardır kadınlar ve genç kızlar tarafından işlenmektedir. Oyalar, kadınların tüm duygu ve düşüncelerini, hayata bakışlarını, başlarından geçenleri kullanılan farklı renk ve motiflerle estetik biçimde hayata yansıttıkları bir süsleme sanatıdır (Aydın, 2015: 768).

Gümüş ve Uray (2018: 357-359) oyaları, kullanılan teknik ve gerece göre iki ayrı grupta ele almıştır. Kullanılan tekniğe göre oya türlerini şu şekilde sıralamıştır;

İğne Oyası: İğne oyaları, iğne üzerine ilmek alarak ve iğneyle ipliği oluşturulan ilmekten çekerek yapılmakta ve bu şekilde kare, üçgen, dikdörtgen şekiller oluşturulmaktadır. Oluşturulan ilmeklerin düzenli ve belirli aralıklarla tekrar edilmesine zürafa adı verilirken; örgü desenlerinin zürafaya tutturulmasına trabzan adı verilmektedir.

Tığ Oyası: Tığ ile zincir yapılarak örülmekte ve elde edilen zincirler birbirine eklenerek motif meydana getirilmektedir. Tığ oyasında birden fazla teknik kullanılmaktadır. Bunlar; dolgu tekniği, sık iğne tekniği, örümcek tekniği, zincir tekniği ve fistık tekniğidir.

Firkete Oyası: Tığ ve firkete kullanılarak yapılmaktadır. U şeklindeki firkete üzerine iplik sarılarak yapılan oya türüdür. Firketenin aralığının geniş olmasına göre oyanın boyutu da değişmektedir. Firketeye sarılan ipliklerin birbirine tutturulması için tığ ile ortasından zincirlenir ve yeni oluşan yapı firketeden çıkarılmaktadır.

Mekik Oyası: Mekik ismi verilen araç ile ipliğin bu araca sarılmasıyla elde edilen oyalardır. Mekik oyası başlı başına yapıldığı gibi bir yere tutturularak da yapılabilmektedir.

Gümüş ve Uray (2018) kullanılan gerece göre oya türlerini ise şöyle sıralamıştır;

Koza Oyaları: Bu oyaların malzemesi koza ve ipektir. Bu oyanın ana motifleri kozalarla yapılmaktadır. Ĭğne ve tığ ile örülmüş kısımlara ise sonradan eklenmektedir.

Yün Oyaları: Bu oyaların malzemesi yün ve çoğu zaman da pamuk ipliğidir. Bu oyaların bir kısmı iğne ve tığla örülmekte ve daha sonra başka yerde işlenmiş kısma eklenerek meydana getirilmektedir.

Mum Oyaları: Bu oyaların motifleri renkli mumlarla yapılmaktadır. Böylelikle diğerlerinden daha kolay ayırt edilebilmektedir. Isı ve dokunmalardan ötürü kolay bozulabildikleri için çeşitleri oldukça azdır.

Boncuk Oyaları: Bu oyalar sentetik iplik ya da ipek ve pamuk kullanılarak yapılmaktadır. İğne ve tığ ile yapılan bu oyaların uçlarına çeşitli boncukların eklenmesiyle boncuk oyaları elde edilmektedir.

Pul Oyaları: Pul oyaları da boncuk oyaları gibi aynı teknikte yapılmaktadır. Plastik pul, metal pul ve balık pulu gibi pul çeşitleri kullanılarak elde edilmektedir. 


\section{HALK KÜLTÜRÜNDE OYALARIN YERİ}

Oyalar Anadolu'nun her yöresinde onları icra edenlerin elinde kültürel ve sosyal etkenlerle bağlantılı olarak farklı isimler almaktadır. Folklorik açıdan bakıldığı zaman oyalar insanımızın duygu ve düşüncelerini sözle ifade edemediği veya söyleyemediğinde, sözsüz iletişim aracı olarak anlam yüklü motiflerle karşımıza çıkmaktadır. Oyalar Türk halk kültüründe pek çok mesaj barındıran, sembolik anlamlar taşıyan el sanatı ürünleridir. Yörelere göre çeşitli anlamlar taşımakla birlikte Anadolu'da sümbül aşkın, umudun ve bekâretin sembolüdür. Âşık olan genç kızlar mor renkli sümbül oyaları, nişanlı olan kızlar ise pembe renkli sümbül oyaları olan yazmalar takarak gönül durumlarını belli etmektedirler. Beyaz renkli sümbül oyası ise kızların sevgililerine temiz duygularla bağlı olduğunu göstermektedir. Nergis motifli oya umutsuz kadını, badem çiçeği motifli oya ise kızların sevdiği gençle evlenecek olmasını simgelemektedir. Kocasıyla arası bozuk olan kadınlar ise biber baharı oyası kullanırken; biber motifli oya yazması takan gelinin ise mutsuz olduğunu göstermektedir (Aydın, 2015: 769). Halk kültürü içerisinde eşinin gözünün dışarıda olduğunu göstermek isteyen kadın iki farklı renkte gül oyası işlemektedir. Gelinler erik çiçeği oyası kullanırken, genç hamile kadınlar müjde oyası, çocuğu olmayanlar ise yas oyası işleyip yazmalarında kullanmaktadırlar (Yeşilyurt, 2008: 65).

Anadolu kadın başlıklarında oyalar, geleneksel baş süslemeleriyle birlikte kullanılan bir sanat sahası oluşturmuştur. Orta Asya ve Anadolu uygarlıklarının birbirinden etkileşerek zengin bir sentez oluşturduğu Anadolu kadın baş süslemelerinde; fes, tepelik, hotoz, takke, tepelik gibi çeşitli isimlerle anılan başlıklarla birlikte oyaların kullanıldığını sınırlı da olsa gözlemlemek mümkündür (Özder, 1999: 9). Geleneksel giyim-kuşam kültürünün devam ettiği bazı bölgelerde, gündelik yaşamda veya dügün ya da kına gecesi gibi özel gün ve gecelerde bu başlıkların oyalı krep ve yazmalarla birlikte kullanıldığı bilinmektedir. Günümüzde hatıra olarak saklanan bu başlıklara sınırlı da olsa rastlamak mümkündür. Fotoğraf '1'de Sivas yöresine ait bir tepelikle birlikte oyalı yazmanın kullanıldığı görülmektedir.

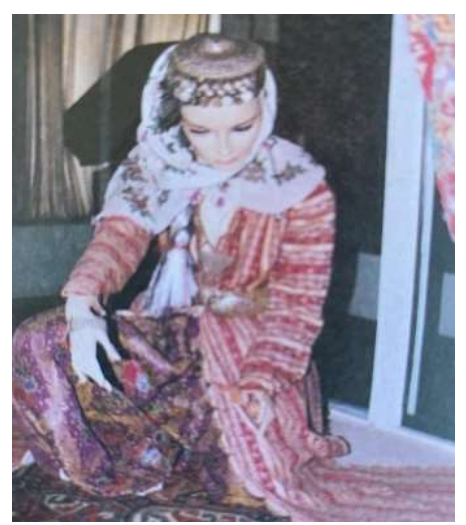

Fotoğraf 1: Sivas Müzesi'ne ait bir tepelik ile birlikte kenarları oyalı yazmanın kullanımına ait bir görsel.

\section{MATERYAL ve YÖNTEM}

Bu çalışmanın materyalini Sivas ili Divriği İlçesi Kemenkeş köyüne ait 12 adet oyalı yazma ve tülbent oluşturmaktadır. Ürünler var olduğu halleri ile incelenmiş olup, araştırmada veri toplama aracı olarak bilgi formu kullanılmıştır. Kullanılan oyaların türü, motif kaynakları, zeminde ve oya 
yapımında kullanılan renkler, oyalarda kullanılan iplik türü ve gereçlere ait özellikler incelenerek bilgi formlarına kaydedilmiş ve ürünlerin fotoğrafları çekilmiștir. Elde edilen veriler uygun görülen konu başlıkları altında tablo haline getirilerek sıklık dağılımları ve yüzdelik gibi istatistiksel yöntemlerle değerlendirilmiş ve yorumlanmıştır. Araştırma sırasında oya sahibi bireylerle yapılan görüşmelerde kaynak kişilerden elde edilen bilgilere de çalışma içerisinde yer verilmiştir. Alan araştırması yapıldığı ve kaynak kişilere de başvurulduğu için Kocaeli Üniversitesi Sosyal ve Beşeri Bilimler Etik Kurulu'ndan 08.07.2021 tarihli 86762 sayılı etik kurul onayı/izni alınarak çalışmaya yön verilmiştir. ${ }^{2}$

\section{SIVAS İLİ DIVRIGĞI İLÇESİ KEMENKEŞ KÖYÜ OYALARININ ÖZELLÍKLERİ}

Bu bölümde araştırma kapsamında incelenen Sivas ili Divriği ilçesi Kemenkeş köyüne ait yazma ve tülbentlerde kullanılan oyaların türü, kullanılan motif kaynakları, zeminde ve oya yapımında kullanılan renkler, oyalarda kullanılan iplik türü ve gereç özelliklerine ilişkin bulgulara yer verilmiştir.

\subsection{Kullanılan Oya Türleri}

Araştırma kapsamında incelenen yazma ve tülbentlerde kullanılan oya türlerine ait veriler incelenerek tablo 1'de sunulmuştur.

Tablo 1.

Yazma ve Tülbentlerde Kullanılan Oya Türlerinin Dağılımı

\begin{tabular}{|l|c|c|}
\hline Kullanılan oya türleri & $\mathbf{n}$ & $\mathbf{0}$ \\
\hline Boncuk oyası & 7 & 58,33 \\
\hline İğne oyası & 3 & 25,01 \\
\hline Tığ oyası & 1 & 8,33 \\
\hline Pul oyası & 1 & 8,33 \\
\hline Toplam & $\mathbf{1 2}$ & $\mathbf{1 0 0}$ \\
\hline
\end{tabular}

Tablo 1 incelendiğinde araştırma kapsamında incelenen yazma ve tülbentlerin \% 58,33'ünde boncuk oyası, \% 25,01'inde iğne oyası, \% 8,33'ünde tığ oyası ve diğer \% 8,33'ünde ise pul oyası kullanıldığı tespit edilmiştir. İncelenen ürünlerin yarıdan fazlasında boncuk oyası kullanıldığı anlaşılmıştır. Yörede kullanılan diğer oya türleri arasında iğne oyası, tığ oyası ve pul oyası bulunmaktadır.

\subsection{0yalarda Kullanılan Motif Kaynakları}

Araştırma kapsamında incelenen oyalarda kullanılan motif kaynakları ait veriler incelenerek tablo 2'de sunulmuştur.

\footnotetext{
${ }^{2}$ Belge doğrulama kodu: BSRZ5S8V3Y / Belge doğrulama adresi: https://turkiye.gov.tr/kocaeliuniversitesi-ebys
} 
Tablo 2 .

Oyalarda Kullanılan Motif Kaynaklarının Dağılımı

\begin{tabular}{|l|c|c|}
\hline $\begin{array}{l}\text { Kullanılan motif } \\
\text { kaynakları }\end{array}$ & $\mathbf{N}$ & $\mathbf{\%}$ \\
\hline Bitkisel motifler & 10 & 83,33 \\
\hline Geometrik motifler & 2 & 16,67 \\
\hline Toplam & $\mathbf{1 2}$ & $\mathbf{1 0 0}$ \\
\hline
\end{tabular}

Tablo 2 incelendiğinde araştırma kapsamında değerlendirmeye alınan ürünlerin \% 83,33'ünde bitkisel kaynaklı motiflerin kullanıldığı görülürken, sadece iki üründe $\% 16,67$ 'lik bir oranla geometrik kaynaklı motiflerin tercih edildiği tespit edilmiştir.

\section{3.Ürünlerde Kullanılan Renkler}

Araştırma kapsamında incelenen yazma ve tülbentler ile oya yapımında kullanılan renklere ait veriler incelenerek tablo 3'de sunulmuştur.

Tablo 3.

Kullanılan Renklerin Dağılımı

\begin{tabular}{|l|c|c|c|c|}
\hline \multirow{2}{*}{$\begin{array}{l}\text { Kullanılan } \\
\text { renkler }\end{array}$} & \multicolumn{2}{|c|}{ Oyada } & \multicolumn{2}{c|}{ Zeminde } \\
\cline { 2 - 5 } & n & \% & n & \% \\
\hline Beyaz & 11 & 91,66 & 8 & 66,66 \\
\hline Yeşil & 4 & 33,33 & - & - \\
\hline Sarı & 3 & 25 & - & - \\
\hline Mavi & 4 & 33,33 & 1 & 8,33 \\
\hline Pembe & 3 & 25 & - & - \\
\hline Mor & 3 & 25 & - & - \\
\hline Siyah & - & - & 2 & 16,66 \\
\hline Kahverengi & 1 & 8,33 & - & - \\
\hline Kırmızı & 2 & 16,66 & - & - \\
\hline Narçiçeği & - & - & 1 & 8,35 \\
\hline
\end{tabular}

Tablo 3 incelendiğinde araștırma kapsamında değerlendirmeye alınan ürünlerin zeminlerinde \% 66,66'sında beyaz, \% 16,66'sında siyah ve bir üründe ise mavi ile narçiçeği renklerinin kullanıldığı anlaşılmıştır. Oya yapımında ise \% 91,66'sında beyaz, \%33,33'ünde yeşil \%33,33'ünde mavi, \% $25^{\prime}$ inde sarı, $\% 25$ 'inde pembe, \% 25'inde mor, \% 16,66'sında kırmızı ve \% 8,kahverengi renkler 8,33'ünde ise kahverenginin kullanıldığı tespit edilmiştir.

İncelenen ürünlerin zemininde yoğun olarak beyaz rengin kullanıldığı anlaşılmıştır. Oya yapımında ise büyük çoğunlukta beyaz rengin kullanıldığı görülmüştür. Bunu yeşil, mavi, sarı, pembe, mor renkleri izlemektedir. 


\subsection{0yalarda Kullanılan İplik Türü}

Araştırma kapsamında incelenen oyaların yapımında kullanılan iplik türlerine ait veriler incelenerek tablo 4'de sunulmuştur.

Tablo 4.

Oyalarda Kullanılan İplik Türlerinin Dağılımı

\begin{tabular}{|l|c|c|}
\hline Kullanılan İplik Türü & $\mathbf{n}$ & $\mathbf{\%}$ \\
\hline Sentetik & 12 & 100 \\
\hline Toplam & $\mathbf{1 2}$ & $\mathbf{1 0 0}$ \\
\hline
\end{tabular}

Tablo 4 incelendiğinde araştırma kapsamında değerlendirmeye alınan ürünlerin tamamında sentetik iplik kullanıldığı tespit edilmiştir.

\subsection{0yalarda Kullanılan Gereçler}

Araştırma kapsamında incelenen oyalarda kullanılan gereçlere ait veriler incelenerek tablo $5^{\prime}$ de sunulmuştur.

\section{Tablo 5 .}

Oyalarda Kullanılan Gereçlerin Dă̆ılımı

\begin{tabular}{|l|c|c|}
\hline Kullanılan Gereçler & $\mathbf{n}$ & $\mathbf{\%}$ \\
\hline Boncuk & 7 & 58,33 \\
\hline Pul & 1 & 8,33 \\
& & \\
\hline
\end{tabular}

Tablo 5 incelendiğinde araştırma kapsamında değerlendirmeye alınan ve yapımında gereç kullanılan ürünlerin \% 58,33’ünde boncuk, \% 8,33'ünde pul kullanıldığı tespit edilmiştir.

\section{SIVAS İLİ DİVRİĞİ İLÇESİ KEMENKEŞ KÖYÜ OYALARINDAN ÖRNEKLER}

Bu bölümde araștırma kapsamında incelenen Sivas ili Divriği ilçesi Kemenkeș köyüne ait 12 adet oyalı yazma ve tülbent örneğinin görselleri sunulmuştur. Bu görseller Hümeyra Koç (K.K.1) ve Arife Karakuş (K.K.2) ile yapılan derlemeler sonucunda elde edilmiştir. Elde edilen bu oyalar; boncuk, firkete, tı̆̆ iğne, pul oyalarından oluşmaktadır ve tamamına yakını bitkisel bezemedir. Kaynak kişiler, ortaya çıkan oyanın görünümüne göre yöreye ait özel isimlendirmelerde de bulunmuşlardır. 


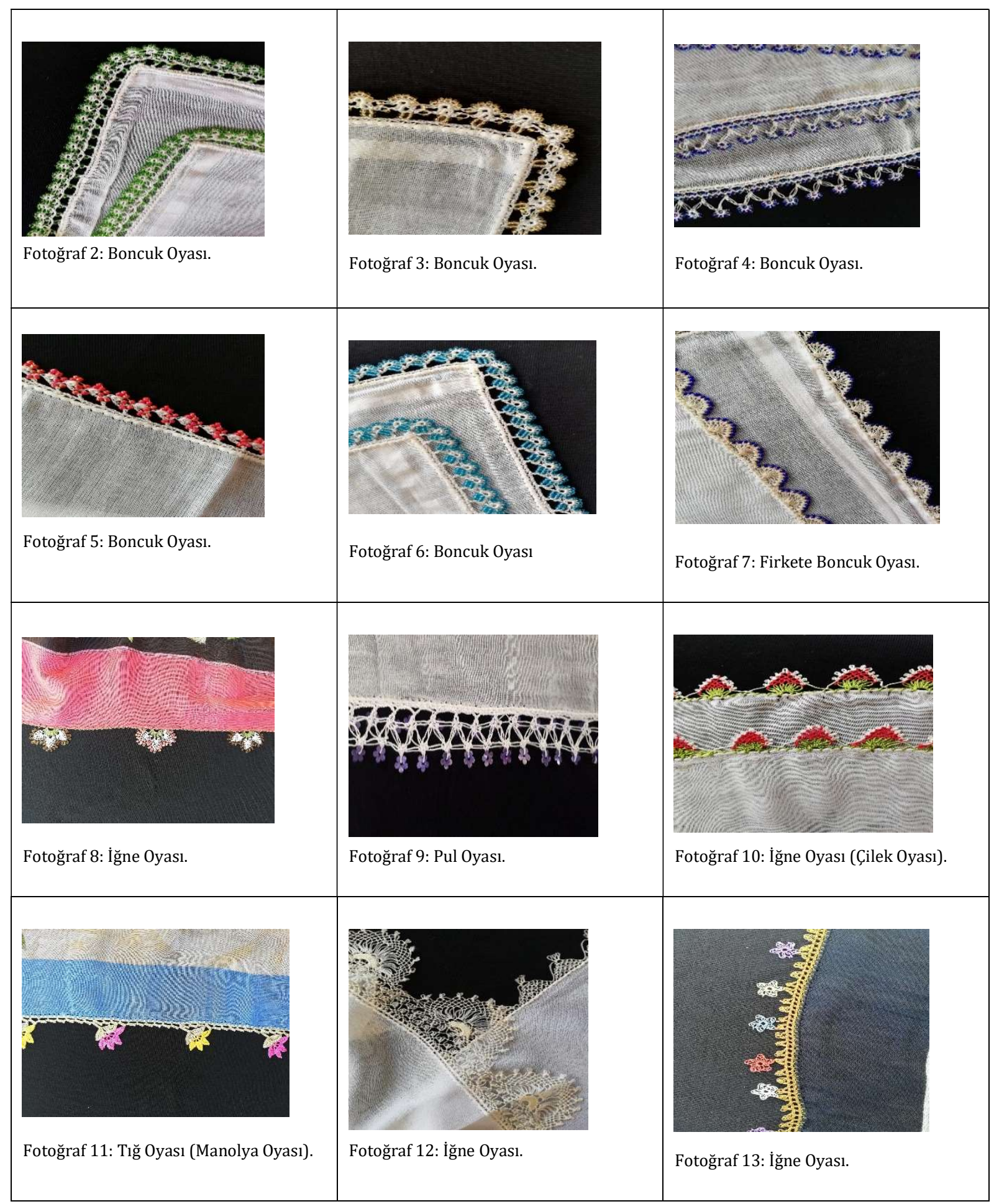




\section{SONUÇ}

Anadolu'ya göç ederek gelen Türkler, kendilerine has giyim şekilleriyle birlikte bu kiyafetlerini de geldikleri topraklara uyumlu hale getirmişlerdir. Oyaların yemeni, yazma, krep gibi baş bağlamada kullanılan eşyaları süslemelerinin yanı sıra tepelik, alınlık, oyalı gibi başlıklarla da kullanıldığı bilinmektedir. Giyim-kuşamın en çok kullanılan aksesuarları arasında olan oyalar; süslenme amacının dışında çeşitli anlamlar da ifade etmektedir.

Sivas ili Divriği ilçesi Kemenkeş köyü kadınları baş bağlama geleneği içerisinde oyalı yazma ve tülbentler kullanmaktadır. Oyalar eski dönemlerde kadınlar tarafından özel olarak başa takılan fes ve alınlıklarla birlikte kullanılırken, günümüzde oyalar sadece yazma ve tülbentlerde kullanılarak örtünme geleneğinin bir parçası olmuştur. Eskiden bireylerin maddi durumlarına göre feslerin alın kısmına madeni paralar da takılırdı. Bazen madeni paraların yerini el yapımı oyalar da almaktaydı. Başa takılan bu fesler genellikle kırmızı renkli olup, başta durması için kenarları oyalı yazmalarla desteklenmekteydi. Bu sayede fesin düşmesi de engellenmiş oluyordu. Günümüzde bu gelenek devam etmemekle birlikte fes kullanımı iki ya da üç kuşak öncesinde yaygın şekilde kullanılmakta olduğu öğrenilmiştir.

Araştırma kapsamında incelenen yazma ve tülbentlerin yapım tarihinin 20 ile 30 yıl öncesine ait olduğu anlaşılmıştır. İstatiksel verilere göre ele alınan oyalarda pula göre boncuk türünün daha çok tercih edildiği ve verilerin tablolarında kadınların yöre kapsamında doğadan esinlenerek bitkisel bezemelere ağırlık verdiği görülmektedir. Boncuk oyalarının beyaz renk tülbentlerin etrafına işlenmiş olduğu ve yörede beyaz tülbentlerin özellikle yeni doğum yapan kadınlar ile yaşlıların kullanımına yönelik olarak hazırlandığı edinilen bilgiler arasındadır. Bunun en önemli sebebi ise bahsi geçen kadınların içinde bulundukları dönemi gösterişten uzak ve daha sade geçirmeleri gerektiği içindir. Kırmızı renk boncuk oyalı tülbentler lohusa kadınları al basmasından koruması inancıyla yeni doğum yapmış kadınlar tarafından kullanılırken; yeşilin huzuru simgelediği ve ruha iyi geldiği düşüncesiyle birlikte de yaşlı kadınlar kullanıldığı tespit edilmiştir.

İncelenen yazma ve tülbentlerin oyalarında yoğun olarak bitkisel kaynaklı motiflerin kullanıldığı anlaşılmıștır. Yörede kullanılan motiflere benzetmeler yoluyla isim verildiği ya da yöre kadınının oyaları oluştururken en sevdiği çiçekleri kendisine konu olarak seçtiği tespit edilmiş olup, manolya ve yonca oyaları en çok bilinen motifler olarak dikkat çekmektedir. Araştırma kapsamında incelenen yazma ve tülbentlerde kullanılan oyaların yapımında süsleyici gereç olarak boncuk ve pul kullanıldığı tespit edilmiştir. Kaynak kişilerden edinilen bilgilere göre yöre kadınlarının eski dönemlerde oya yapımında daha çok ipek ibrişimli iplik tercih ederken, günümüzde tamamen sentetik iplik kullanmayı tercih ettikleri öğrenilmiștir.

Yöre kültüründe yazma ve tülbentlerin çoğunluğu çeyiz geleneği içerisinde yakın akraba ve hatırı sayılır dostlara hediye edilmektedir. Günümüzde değişen hayat şartları, giyim-kuşam ve süslenme kültürünün değişmesiyle birlikte genç neslin oyalara ilgisi azalmıştır. Bu durum oya kültürünün ulaşılan oya örnekleri aracılığı ile muhafaza edilmesi ve belgelenmesini bir ihtiyaç haline getirmektedir. Anadolu kültürünün gelecek kuşaklara aktarımını sağlaması bakımında bu tür çalışmalar hem belgeleme hem de alanda yapılacak yeni çalışmalara kaynak oluşturması bakımından önemlidir. 


\section{KAYNAKÇA}

Aydın, N. (2015). Türkiye Sahasında Oyalar ve Ad Almaları Üzerine Dil-Kültür, Folklor Bağlamında Bir Değerlendirme. Ö. Çobanoğlu içinde, Dört Kıtada Folklorun İzinde: Prof. Dr. Özkul Çobanoğlu Armağanı (s. 767). Ankara: Aydan Matbaacılık.

Balkanal, Z. (2014). Karadeniz'in İncisi İnebolu Yöresinde Dantel Perdeler. Karadeniz Uluslararası Bilimsel Dergi, 44-54.

Gümüş, G., \& Uray, D. (2018). Oya El Sanatı Üzerine Bir İnceleme. Uluslararası Sosyal Araștırmalar Dergisi, Cilt: 11, Sayı: 55, 356-357.

Özder, L. (1999). İç Anadolu Bölgesi Geleneksel Kadın Başlıkları. Ankara: Kültür Bakanlığı Yayınları.

Sönmez, K. (2019). Türk Kültüründe Oyalar: Gaziantep İli Nizip İlçesi Örnekleri. Ídil, Sayı: 65, 107.

Yeşilyurt, E. (2008). Anadolu Kadın Baş Bağlamasının İletişimdeki Dili. Halk Kültürü'nde GiyimKuşam ve Süslenme Uluslar Arası Sempozyumu Bildirileri (s. 64-67). Eskișehir: Eskişehir Osmangazi Üniversitesi Yayınları.

Yıldız, G., \& Öğ̈̈, L. (2020 Cilt: 6 Sayı: 1). Tanım, Terim ve Kavramları İle Dantel. İnönü Üniversitesi Kültür ve Sanat Dergisi, 126-142.

\section{Kaynak Kişiler}

Arife KARAKUŞ, Sivas, Ev Hanımı, 31.12.1957 (12.03.2021 tarihinde görüşüldü).

Hümeyra KOÇ, Sivas, Ev Hanımı, 08.08.1971 (17.03.2021 tarihinde görüşüldü). 